
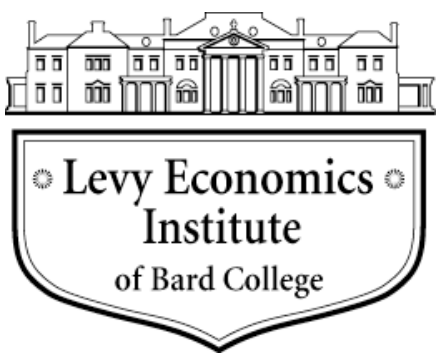

Working Paper No. 814

\title{
Distribution-led Growth in the Long Run
}

by

\author{
Michalis Nikiforos* \\ Levy Economics Institute of Bard College
}

\section{September 2014}

*mnikifor@levy.org

The Levy Economics Institute Working Paper Collection presents research in progress by Levy Institute scholars and conference participants. The purpose of the series is to disseminate ideas to and elicit comments from academics and professionals.

Levy Economics Institute of Bard College, founded in 1986, is a nonprofit, nonpartisan, independently funded research organization devoted to public service. Through scholarship and economic research it generates viable, effective public policy responses to important economic problems that profoundly affect the quality of life in the United States and abroad.

\author{
Levy Economics Institute \\ P.O. Box 5000 \\ Annandale-on-Hudson, NY 12504-5000 \\ http://www.levyinstitute.org
}

Copyright (C) Levy Economics Institute 2014 All rights reserved

ISSN $1547-366 \mathrm{X}$ 


\begin{abstract}
The paper examines the long-run fluctuations in growth and distribution through the prism of wageand profit-led growth. We argue that the relation between distribution of income and growth changes over time. We propose an endogenous mechanism that leads to fluctuations between wage- and profitled periods. Our model is a linear version of Goodwin's predator-prey model, but with a reversal of the roles for predator and prey: the growth rate acts as the predator and the distribution of income as the prey. These fluctuations need to be taken into account when someone estimates empirically the effect of a change in distribution on utilization and growth. We also examine our argument in relation to the double movement of Karl Polanyi, the Kuznets curve, and the theories of long swings proposed by Albert Hirschman and Michal Kalecki.
\end{abstract}

Keywords: Distribution-led; Long Swings; Oscillations; Predator-prey

JEL Classifications: B22, E11, E12, E21, E22, E32 


\section{INTRODUCTION}

Over the last few years, distribution of income has been occupying an increasingly central role in the political and macroeconomic debate in the US and elsewhere, and an increasing number of economists agree that a redistribution of income is a prerequisite for sustainable growth in the future. The examples are abundant. The recent Occupy Wall Street movement was built around distributional issues ("We are the 99\%" was its main motto), and Thomas Piketty's Capital in the Twenty-First Century (2014), an economics book on distribution of income, remained at the top of the best-sellers list for many weeks (The American media were puzzled how a 700-page, heavily appendixed tome packed with words like "disequilibria" and "Ricardian" could be so popular). Finally, Janet Yellen, the new chairwoman of the Federal Reserve, during her congressional confirmation hearings pointed to the inequality of income as one of the main problems of the US economy and drags on future growth.

This situation comes in stark contrast with the recent past, when politicians, policy makers and academic economists mostly ignored distribution-related issues. Who could imagine the chairman of the Fed talking about distribution of income ten or fifteen years ago? It is thus an interesting endeavor to try to understand what are the reasons that led to this revival in the interest in the distribution of income and its relation with growth.

The issue at hand cannot be treated in purely economic terms. We need a broader perspective that can take into account institutions, social norms, and other political factors. A convenient way to deal with this nexus is provided by the Kaleckian model of growth and distribution. The origins of the model can be traced back to the classical political economists and, of course, John Maynard Keynes and Michal Kalecki (e.g.,1971). In its modern form it has been developed by Steindl (1952), Rowthorn (1981), Taylor (1983, 1990, 2004), Dutt (1984, 1990), Amadeo (1986), Kurz (1990), and Marglin and Bhaduri (1990). Within the Kaleckian framework, distribution is one of the main determinants of the rate of growth and the macroeconomic performance of the economy. The effect of a change in the distribution of income is not certain a priori. When an increase in the wage share boosts demand and growth, the economy is said to be wage-led; in the opposite case it is profit-led. 
This poses the question - the answer to which will also help us understand the recent developments: Can an economy be universally profit-led or on the other hand universally wage-led? This question has received surprisingly little attention in the literature. An economy usually is considered to be either profit-led or wage-led. However, if this was true, a continuous increase in the share of profits or wages, respectively, would lead to a continuous increase in the growth rate, and the maximum growth rate would be achieved when the wage or the profit share is zero. Clearly, this could not be the case. Therefore, from a purely logical point of view, the answer to the question of universality is negative.

If one starts from this logical conclusion, it seems possible that an economy goes through phases of wage- and profit-led growth. The aim of the present paper is to present an endogenous mechanism that drives the economy through these phases. Our argument is founded on two main pillars. On the one hand, we assume that the distribution of income is fundamentally unstable. The more powerful each class becomes, the greater is its ability to further increase its power and share of income. At the same time, the direction of the distribution of income is influenced by its potential effect on growth. In a wage-led economy the share of wages will tend to increase, and in a profit-led economy it will tend to decrease.

On the other hand, the pursuit of distribution-led growth contains the seeds of its own destruction. The pursuit of wage-led growth makes the economy less wage-led or more profit-led. Similarly the pursuit of profit-led growth will make the economy less profit-led (or more wage-led). These two opposing forces create oscillations of growth and distribution in the long run.

The argument is stated in terms of a stripped-down version of the Kaleckian model, where the reaction of the economy to changes in distribution depends on the propensities to invest and save out of profits. Therefore the mechanism we propose is based on changes in these propensities as the distribution of income changes.

As we shall see in more detail below, our model is a linear version of the Goodwin (1967) predator-prey model, but with a reversal of roles for the predator and the prey. In our model, it is the growth rate potential (and indirectly the growth rate itself) that acts as the predator, and the distribution 
of income that acts as a prey. This is another way to approach the symbiosis of workers and capitalists and provides some important insights in an attempt to understand the long swing of growth and income distribution during the twentieth century. The crisis of the 1930s was one of the most important factors that led to the redistribution of income in favor of wages, which took place at that time and after World War II. This redistribution of income formed the basis for the growth of the so-called Golden Age, the three decades after the War, but exhausted its potential in the 1970s and led to the crisis of that decade. In turn, the crisis of the 1970s was an essential prerequisite for the redistribution of income in favor of profits that has taken place since and led to the current crisis.

With the same logic we can answer our original question. It was only after the current crisis that people started realizing the magnitude of the redistribution of income that has taken place since the early 1980s and its harmful effect on the growth potential of the economy. Trough this prism it it not hard to understand the motto of the Occupy Wall Street movement, the popularity of the book by Piketty or Yellen's statement.

This kind of interpretation of long swings is related to what Karl Polanyi called "the double movement" and can explain the famous hump-shaped curve proposed by Simon Kuznets. Moreover, we examine our interpretation in relation to other theories of long swings by Hirschman, Kalecki, Schumpeter and Minsky.

Finally, our argument raises some issues related to the empirical examination and estimation of wage-ledness and profit-ledness. If an economy goes through different phases, the usual practice of using long-time series to determine whether an economy is wage-led or profit-led is wrong.

The paper proceeds as follows. In the next section we present a canonical stripped-down version of the Kaleckian model of growth and distribution, and we briefly discuss its behavior in the short run. In section 3 we formulate our argument about the trajectory of growth and distribution in the long run. Section 4 explains the consequences of our analysis for the econometric estimation of the effect of a change in distribution on growth. In section 5 we discuss the relation of our model to the predator-prey specification proposed by Richard Goodwin. In sections 6 through 8 we examine our model in the light of the theories of long swing by Polanyi, Kuznets, Hirschman, Kalecki, Schumpeter 
and Minsky. Section 9 concludes.

\section{THE SHORT RUN}

In our discussion we distinguish between the short run and the long run. In the short run, the distribution of income, as well as the reaction of investment and saving to distribution and utilization, are taken to be given and thus exogenous.

The short run can be modeled according to a simple version of the Kaleckian—or post Keynesian, or structuralist - model of a closed economy without a government sector. The main determinants of the macroeconomic performance of the economy are aggregate demand and the distribution of income. In turn, demand is determined by the saving behavior of workers and capitalists and the investment behavior of the firms. The income of the economy is distributed between wages and profits. For the purposes of this paper, we will assume that in the short run the distribution of income is constant and exogenously given.

Investment (normalized for capital stock) can be defined as $g^{i}=I(\pi, u)$, where $\pi$ is the profit share and $u$ is the rate of capacity utilization. Both $I_{\pi}$ and $I_{u}$-the marginal propensities to invest out of profits and utilization (the subscript stands for the partial derivative for this variable) - are positive. On the other hand, total saving (normalized for the capital stock) is $g^{s}=S(\pi, u)$. Again $S_{u}$ and $S_{\pi}$ (the marginal propensities to save out of profits and utilization) are positive; the latter because capitalists save more than the workers. We will assume a simple linear functional form for both the investment and saving functions

$$
\begin{gathered}
g^{i}=\gamma+g_{u}^{i}\left(u-u^{d}\right)+g_{\pi}^{i}\left(\pi-\pi^{*}\right) \\
g^{s}=s_{0}+g_{u}^{s} u+g_{\pi}^{s}\left(\pi-\pi^{*}\right)
\end{gathered}
$$

where $\gamma$ and $s_{0}$ are exogenous constants, $u^{d}$ is the "normal" or "desired" level of utilization, which for the purposes of this paper, is assumed to be constant, and $\pi^{*}$ is the long run center of gravity 
of distribution of income, also assumed to be constant. This kind of specification of the investment function is standard in the literature. The addition of $u^{d}$ and $\pi^{*}$ means that investment does not react to the level of utilization itself, but rather to its deviation from its long run value and that the investment decisions do not depend on the magnitude of profitability itself, but from its deviation from its long run center of gravity. The use of $\pi^{*}$ in the saving function is less standard. However, we could convincingly argue that the consumption decisions of the capitalist households are based not on the level of their income, but rather on its deviation from what they would consider as its "normal" long run level.

Moreover, $g_{u}^{i}, g_{\pi}^{i}, g_{u}^{s}, g_{\pi}^{s}>0$ are the marginal propensities to invest and save out of utilization and profits respectively and are also assumed to be constant in the short run. As we will see in the next section the propensities out of profits play an important role in the long run.

Since distribution is exogenous in the short run, equations (1) and (2) are enough to determine the equilibrium of the system, where investment is equal to saving, $g^{i}=g^{s}$. The short run equilibrium rate of utilization is:

$$
u^{\prime}=u_{0}+\frac{g_{\pi}^{i}-g_{\pi}^{s}}{g_{u}^{s}-g_{u}^{i}}\left(\pi-\pi^{*}\right)
$$

where $u_{0}=\frac{\gamma-s_{0}-g_{u}^{i} u^{d}}{g_{u}^{s}-g_{u}^{i}}$ and the equilibrium growth rate is:

$$
g^{\prime}=g_{0}+\frac{g_{\pi}^{i} g_{u}^{s}-g_{\pi}^{s} g_{u}^{i}}{g_{u}^{s}-g_{u}^{i}}\left(\pi-\pi^{*}\right)
$$

where $g_{0}=\gamma+g_{u}^{i} u_{0}$. The equilibrium is assumed to be stable, or that $g_{u}^{s}-g_{u}^{i}>0$. This is commonly referred to as the Keynesian stability condition.

What is especially important for our discussion here is the reaction of utilization and the growth rate to changes in the distribution of income. From equation (3) it is easy to see that $\partial u^{\prime} / \partial \pi>0 \Longleftrightarrow$ $g_{\pi}^{i}-g_{\pi}^{s}>0 \Longleftrightarrow g_{\pi}^{i} / g_{\pi}^{s}>1$; an increase in the profit share increases the (equilibrium) utilization rate as long as the propensity to invest out of profits is higher than the propensity to save. Similarly, from equation (4) 


$$
\partial g^{\prime} / \partial \pi>0 \Longleftrightarrow g_{\pi}^{i} g_{u}^{s}-g_{\pi}^{s} g_{u}^{i}>0 \Longleftrightarrow g_{\pi}^{i} / g_{\pi}^{s}>g_{u}^{i} / g_{u}^{s}
$$

An increase in the profit share leads to an increase in the growth rate if the ratio of the propensity to invest out of profits to the propensity to save out of profits is bigger than the ratio of the respective propensities out of utilization. Given the Keynesian stability condition, this condition is less demanding compared to the condition for utilization.

Based on this we can define our economy as profit-led if $\partial g^{\prime} / \partial \pi>0$ or according to equation (5) if $g_{\pi}^{i} g_{u}^{s}-g_{\pi}^{s} g_{u}^{i}>0$. On the other hand, if an increase in the profit share leads to a decrease in the rate of growth $\left(\partial g^{\prime} / \partial \pi<0\right)$ our economy is wage-led. From equation (5) the sufficient condition for that is $g_{\pi}^{i} g_{u}^{s}-g_{\pi}^{s} g_{u}^{i}<0$.

We can now define the central variable of the present paper: $\lambda=g_{\pi}^{i} g_{u}^{s}-g_{\pi}^{s} g_{u}^{i}$. From the preceding discussion $\lambda$ expresses what we can call the degree of distribution-ledness of the economy. A high (positive) $\lambda$ means that a redistribution of income toward profits would have a strong positive effect on demand and growth. On the other hand, a highly negative $\lambda$ means that a redistribution of income toward wages would increase demand and growth.

Distribution-ledness, $\lambda$, expresses a potential. An economy might be wage-led but the distribution of income might remain unchanged or even move in the opposite direction toward a higher profit share (or vice versa). In such a case the potential of the economy is wasted and the economy is sinking into a crisis.

\section{THE LONG RUN}

\subsection{Distribution}

The distribution of income between workers and capitalists expresses the state of the power relation between these two classes and is determined by several social norms and institutional factors. An interesting question is how do these norms and factors evolve in the long run? We will make three assumptions. First, the power relations between the two classes is unstable. In other words, the more powerful a class is, the more the balance of power and the distribution will tend to move in its favor. 
Think, for example, of the situation in the United States over the last thirty years. The more powerful the capitalist class has become, the more it has tried and succeeded to push the balance in its favor, through lobbying, control of the media, etc. On the other hand a similar situation is possible in the opposite direction. For example an increase in the wage share indicates that participation in the trade union or labor parties can be beneficial; that can lead to an increase in their membership and their power, which in turn makes a further increase in the wage share more possible.

The second assumption we make is that the direction of the distribution depends on the "distributionledness" of the economy. The more profit-led an economy is, the more possible it becomes that the profit share will increase and vice versa. The reason for that is simple. As long as the "distributionledness" is in tune with the direction of the distribution of the income, the economy will grow. The problem arises when there is a conflict between them. If an economy is, say, wage-led and the profit share keeps increasing, the growth rate will decrease. The ensuing crisis and the conditions that this crisis creates will put a break on the increase in the profit share. It is not coincidental that the changes in the direction of distribution in the 20th century were preceded by big crises.

Finally, we will assume that there are lagged effects on the dynamics of income distribution. The institutions and social norms that define these dynamics have a historical memory, so the conditions that predominate in a certain period will not only affect the dynamics of the next period, but will continue to have an influence in the future.

Mathematically, we can express these assumptions as $\dot{\pi}=\int_{0}^{t} f[\pi(s), \lambda(s)] d s$ where $\dot{\pi}=d \pi / d t$ is the time derivative of the profit share and $\partial \dot{\pi} / \partial \pi, \partial \dot{\pi} / \partial \lambda>0$. For the purposes of our paper we will assume a simple linear relationship:

$$
\dot{\pi}=\int_{o}^{t} \alpha_{1}\left(\pi(s)-\pi^{*}\right)+\alpha_{2} \lambda(s) d s
$$

where $\alpha_{1}, \alpha_{2}>0$. If we time differentiate both sides, equation (6) can be rewritten as:

$$
\ddot{\pi}=\alpha_{1}\left(\pi-\pi^{*}\right)+\alpha_{2} \lambda
$$




\subsection{The propensities to invest and to save}

\subsubsection{The propensity to invest}

In the long run there is one more set of changes: the propensities to invest and save out of profits change in response to changes in the profit share. With regard to the propensity to invest out of profits we will assume that it decreases as the profit share increases. There are various possible reasons for that. The Keynesian theory of investment recognizes two important roles for profitability in the determination of the investment decisions of the firms. First, past and present profitability provide the basis for the formation of the expectations of the entrepreneurs. Keynes, in The General Theory (1936, ch. 11), defined the present value of these profit flows (net of financial costs) as the marginal efficiency of capital or the demand price for investment. It is possible that as current profitability increases, it becomes - at least after a certain point — less and less important for the formation of the expectations for the future profit flows and that other considerations become more important. An obvious example of these other considerations is the limited size of the market (Kalecki, 1971, ch. 10). In this case the effect of profitability on investment weakens.

Additionally, profitability is important for investment because it is an important source of internal finance for the firm. Increasing profitability provides higher internal finance and that decreases the marginal risk of fixed capital investment, according to the "principle of increasing risk" proposed by Kalecki (1937). Similarly, from the point of view of Minsky (1986, ch. 8), ample internal funds increase the margin of security of the firm and decrease the "lender's risk" and lead in that way to higher investment. Also in this case, these investment-supply considerations may be very important when the profit share is small but weaken as the profits share increases. If we want to use the famous graph with the borrower's and lender's risk proposed by Minsky (1986, figure 8.3) it is possible that as the lender's risk curve shifts to the right, the intersection of the two curves takes place on the horizontal part of the lender's risk curve. After that point, further increases of internal funds do not affect the investment decisions of the firm. Even before that, to the extent that the lender's risk curve is increasing exponentially (as is drawn by Minsky), the marginal effect of a rightward shift of the lender's risk curve is decreasing. This observation explains to a large extent why the US firms increasingly sit 
on their cash instead of investing. ${ }^{1}$

Moreover, an increase in the profit share might be associated with an increase in the power of the shareholders, who demand that an increasing share of the profits is distributed, and less are retained for investment. Finally, the increasing share of profits has historically been associated-before the 1930s but also in the last three-and-a-half decades (the so-called neoliberal era)—with a dominant position of the financial sector. Polanyi (2001) in The Great Transformation referred to haute finance. The neoliberal era has also been called the era of financialization. In conditions like these, as the financial sector gets the upper hand, it is becoming increasingly tempting for the firms to channel their retained profits to the financial markets instead of investing them in physical capital. This channeling can take the form either of share buybacks of the firm itself or of other financial products. ${ }^{2}$

The common result of all these movements is a decrease in the propensity to invest out of profits as the profit share is increasing. We can write this as

$$
g_{\pi}^{i}=\beta_{0}-\beta_{1} \pi
$$

where $\beta_{0}$ and $\beta_{1}$ are positive constants.

\subsubsection{The propensity to save}

On the other hand, the propensity to save increases as the profit share increases and thus the income of the capitalists increases. Keynes in chapter 10 of The General Theory (1936) argues that, as a rule, there will be a tendency of the marginal propensity to consume to diminish as the real income increases. Samuelson (1939, p. 793-795) also discusses the possibility of this kind of behavior of the marginal propensity to consume.

In Figure 1 we present data from the Consumer Expenditure Survey of the Bureau of Labor Statistics for the saving rate of the top $20 \%$ of American households classified according to their in-

\footnotetext{
${ }^{1}$ According to a recent report from the Federal Reserve of St. Louis (Sánchez and Yurdagul, 2013) the "Aggregate Cash and Equivalents of Non-Financial Non-Utility U.S. Firms" increased from close to \$100bn in 1980 to around \$1.6tn in 2011. The ratio of cash to total assets increased from 5\% in the early 1990 s to more than $12 \%$ in 2011.

${ }^{2}$ There is a broad literature on financialization. Some indicative reference include Boyer (2000), Lazonick and O'Sullivan (2000), Stockhammer (2004), Epstein (2005), Orhangazi (2008), Skott and Ryoo (2008).
} 
Figure 1: The Saving Rate of the Top 20\% of the Distribution

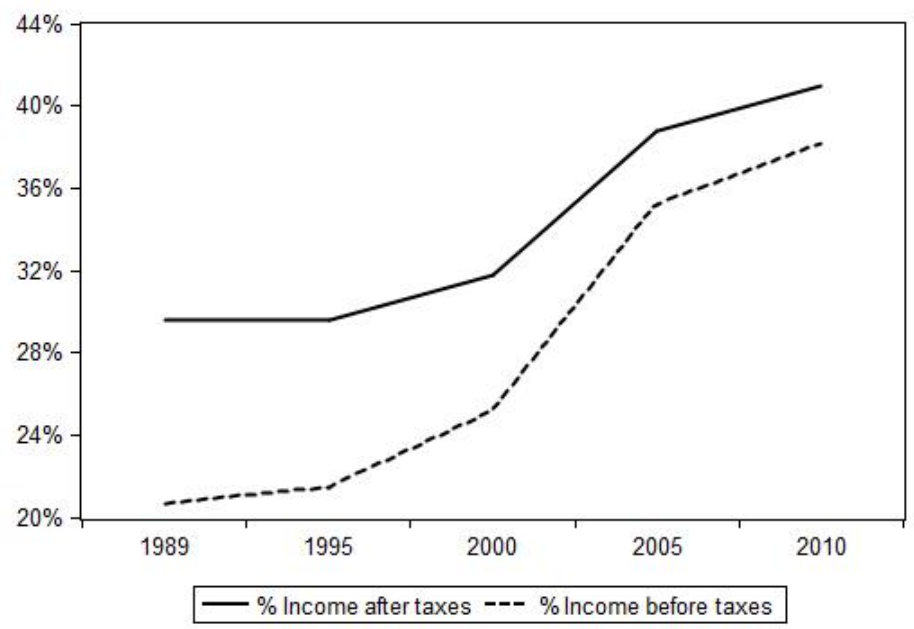

Source: Consumer Expenditure Survey, Bureau of Labor Statistics

come. As we can see, the saving rate of these households has increased as their income share increased. Dynan et al. (2004) analyze in more detail the micro-data from the Consumer Expenditure Survey, as well as the Panel Study of Income Dynamics and the Survey of Consumer Finances. They find a strong positive relationship between saving rates and income (both current income and permanent income).

There are various reasons that can explain this kind of behavior. First of all, no matter how extravagant rich households are, with respect to their consumption, there is only so much that they consume. Therefore as their share of income increases, not only will they save a larger share of their income compared to the middle-class or poor households, but also their saving rate will increase. In other words, we can assume that there is some kind of bliss point. When the capitalist households find themselves close to this bliss point they will increase their saving rate as their income increases further. Ramsey (1928) builds the argument of his seminal “A Mathematical Theory of Saving” on the existence of such a bliss point. ${ }^{3}$

Moreover, if we use the taxonomy of the motives of saving from The General Theory (p. 107-108) an increasing saving rate as the income of a household increases can be justified by the motive to build-up of reserves against unforeseen contingencies, the motive to bequeath a fortune ${ }^{3}$ As it is well know—and evident in the paper itself-this view was also shared by Keynes. 
and finally, the satisfaction of "pure miserliness, i.e. unreasonable but insistent inhibitions against acts of expenditure as such." The first two of these motives are the basis of the modern neoclassical explanations of the differential saving rate between poor and rich households. ${ }^{4}$

We can write this reaction of the propensity to save out of profits to changes in the profit share as

$$
g_{\pi}^{s}=\gamma_{0}+\gamma_{1} \pi
$$

where $\gamma_{0}$ and $\gamma_{1}$ are positive constants.

\subsection{The behavior of the system in the long run}

Equations (8) and (9) define the behavior of $\lambda$ in the long run when the distribution of income varies

$$
\lambda=\left(\beta_{0} g_{u}^{s}-\gamma_{0} g_{u}^{i}\right)-\left(\beta_{1} g_{u}^{s}+\gamma_{1} g_{u}^{i}\right) \pi
$$

This equation taken together with equation (7) and the short run equilibria determine the system in the long run. By substituting(10) into (7) we get

$$
\ddot{\pi}=k_{0}-k_{1} \pi
$$

where $k_{0}=\alpha_{2}\left(\beta_{0} g_{u}^{s}-\gamma_{0} g_{u}^{i}\right)-\alpha_{1} \pi^{*}$ and $k_{1}=\alpha_{2}\left(\beta_{1} g_{u}^{s}+\gamma_{1} g_{u}^{i}\right)-\alpha_{1}$.

The behavior of the system hinges on the parameter $k_{1}$. If it is negative then $\pi$ will monotonically diverge from its steady state value and the system explodes. On the other hand if $k_{1}>0$, the profit share will oscillate around its state value with constant amplitude.

A positive $k_{1}$ means that $\alpha_{2}\left(\beta_{1} g_{u}^{s}+\gamma_{1} g_{u}^{i}\right)>\alpha_{1}$. In (other) words the system does not explode if the stabilizing effect of the changing profit-ledness is stronger than the inherent instability in the distributional dynamics. More precisely, as we mentioned above, the power relation, and thus the

${ }^{4}$ Dynan et al. (2004) provide a summary of the relevant neoclassical literature. They show that within a neoclassical utilitymaximizing framework, this kind of behavior can be derived with the introduction of hyperbolic preferences together with some kind of uncertainty (e.g. large medial expenses) and/or a bequest motive. 
distribution of income between the two classes is unstable, the more powerful a class becomes, the more potential it will have to further increase its power. In our model this instability is expressed by $\alpha_{1}$. However, as (say) the profit share increases, the propensities to invest and save change as well (through $\beta_{1}$ and $\gamma_{1}$ in the model) and the economy becomes less profit-led (or more wage-led) and $\lambda$ decreases. This decrease in $\lambda$ puts pressure on the rate of change of distribution through $\alpha_{2}$. So, if the "restoring" force (expressed by $\alpha_{2}\left(\beta_{1} g_{u}^{s}+\gamma_{1} g_{u}^{i}\right)$ ) is stronger than the unstable tendency of distribution, the system will oscillate around a long run steady state. We will assume that this condition holds and will discuss the dynamics of the system in this case.

Hence, if $k_{1}>0$, the solution to equation (11) can be written as

$$
\pi(t)=\pi^{*}+A \cos \left[\sqrt{k_{1}} t+\phi\right]
$$

where $A$ and $\phi$ are constants of integration ( $\phi$ is sometimes called phase and determines the starting point of the sine wave).

From equation (11) we can derive the value of the steady state of distribution $\pi^{*}=\frac{\beta_{0} g_{u}^{s}-\gamma_{0} g_{u}^{i}}{\beta_{1} g_{u}^{s}+\gamma_{1} g_{u}^{i}}$. Since the propensity to invest out of profits $\left(g_{\pi}^{i}\right)$ is a positive function of $\beta_{0}$ and a negative of $\beta_{1}$ and the propensity to save out of profits $\left(g_{\pi}^{s}\right)$ is a positive function of both $\gamma_{0}$ and $\gamma_{1}$, it is not hard to see that the steady state value of the profit share is a positive function of $g_{\pi}^{i}$ and a negative function of $g_{\pi}^{s}$. This echoes the widow's cruse parable as stated by Keynes in the Treatise (Keynes, 1930), Kaldor's Keynesian theory of distribution (Kaldor, 1955), and of course the famous aphorism attributed to Kalecki that "capitalists earn what they spend, and workers spend what they earn."

If we combine this with equation (10) we get the solution for $\lambda$ in the long run

$$
\lambda(t)=-\lambda_{1} \cos \left[\sqrt{k_{1}} t+\phi\right]
$$

where $\lambda_{1}=\left(\beta_{1} g_{u}^{s}+\gamma_{1} g_{u}^{i}\right) A$. Finally, from these last two equations and equation (4) we derive the solution for the growth rate in the long run 
Figure 2: The Trajectories of $\pi, \lambda$ and $g$

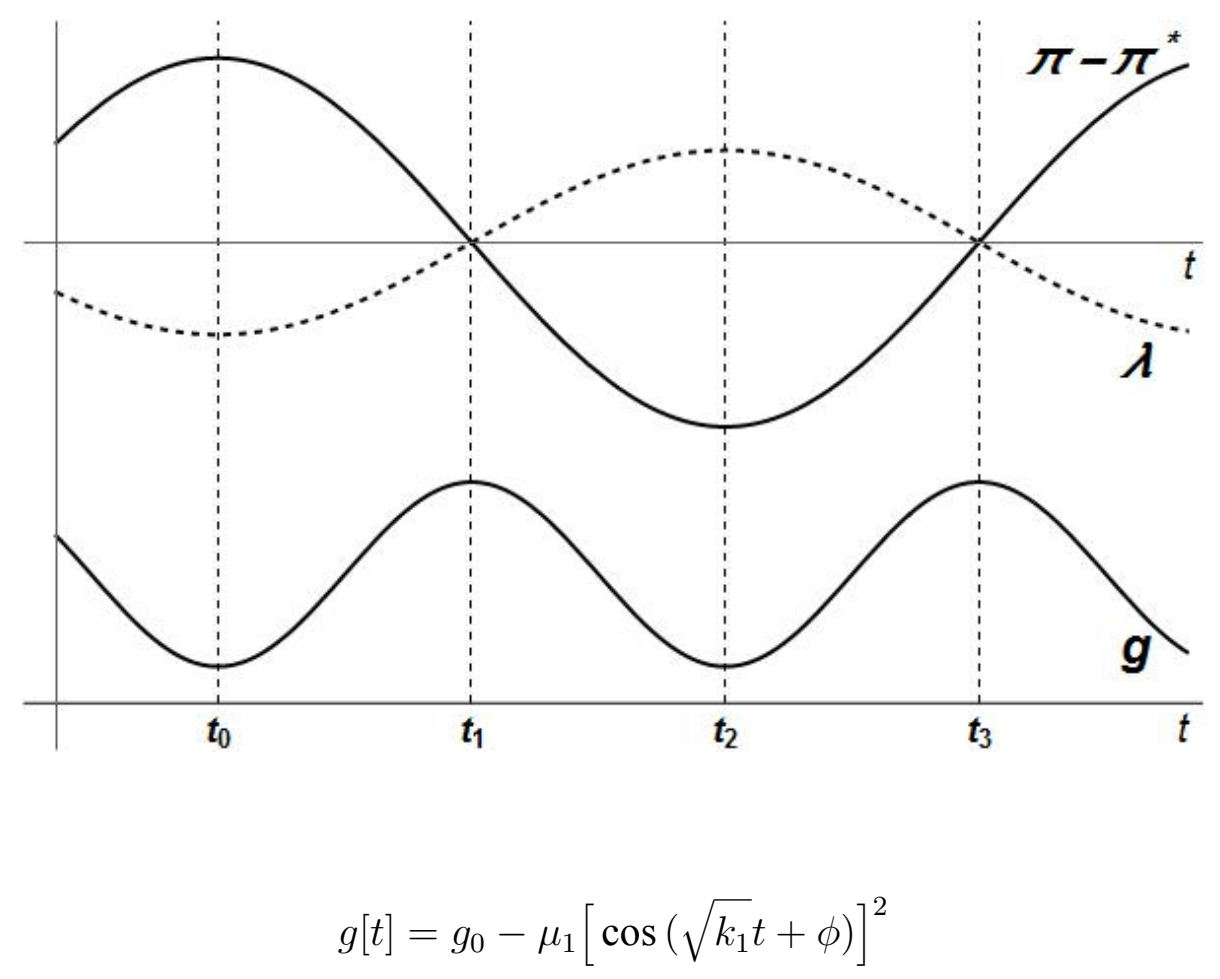

where $\mu_{1}=\frac{\beta_{1} g_{u}^{s}+\gamma_{1} g_{u}^{i}}{g_{u}^{s}-g_{u}^{i}} A^{2}$.

The solutions of the distribution, the profit-ledness and the growth rate, as defined in equations (12), (13) and (14), are presented in Figure 2. To make the expositions clearer, we present the deviation of the profit share from its steady steady value $\left(\pi-\pi^{*}\right)$ instead of the profit share itself. The results are intuitive. If we start at point $t_{0}$ we see that the profit share is at its maximum value and $\lambda$ at its minimum value - thus the economy is strongly wage-led. As a result, the growth rate is low. As the profit share decreases, since the economy is wage-led, the growth rate increases. However, at the same time, the economy becomes less wage-led. At $t_{1}$ the economy is neither wage- or profit-led $(\lambda=0)$ and after that point the economy becomes profit-led. As the profit share keeps decreasing, the growth rate starts decreasing after $t_{1}$. The crisis that follows as the growth rate falls changes the direction of distribution at $t_{2}$. After $t_{2}$ the reverse process begins. The economy is profit-led, and as the profit share increases the growth rate increases as well. The increase of the profit share is accompanied by a decrease in $\lambda$. After $t_{3}$ the economy becomes wage-led and the continuation of the increase in the profit share causes the growth rate to decline. We find ourselves today in a situation like this to the 
right of $t_{3}$.

There is a large number of interesting comments that we could make based on this simple model. We outline them in the following sections.

\section{EMPIRICS OF DISTRIBUTION-LED GROWTH}

According to the argument of the preceding sections, wage-ledness and profit-ledness is not a global property of an economy in time. There are periods that an economy is wage-led and there are periods that it is profit-led. This does not diminish the importance of the concept - quite the contrary; we saw that if distribution moves in a "wrong" direction the economy will end up in a big crisis with a low utilization and growth rate.

Nonetheless, this conclusion has important consequences for the empirical examination and estimation of distribution-ledness in an economy. There is an extensive body of literature (including a paper by the author) that tries to estimate if an economy is profit-led or wage-led. ${ }^{5}$ However, if an economy goes through different phases, it can be problematic to use time series data for an extended period of time in order to determine if an economy is wage-led or profit-led over this whole period, without taking into account that there might have been important changes in the relation between distribution and growth over this extended period.

For example, many studies use data on distribution and growth for the US economy for the whole post-WWII period and reach a conclusion about the "distribution-ledness" of the US economy. It seems highly unlikely that the relation between distribution and growth has been similar in the 1950s, the 1970s and now, the 2010s.

Marglin and Bhaduri (1990) implicitly make this point. When they examine the transition of the American economy from the 1920s to the crisis of the 1930s, the "Golden Age" and its demise they argue that the propensities (mainly to invest) out of profits and thus the slope of the demand (what

\footnotetext{
5 Notable contributions in the empirical literature of wage- and profit-led growth include Bowles and Boyer (1995), Gordon (1995), Barbosa-Filho and Taylor (2006), Stockhammer and Onaran (2004), Onaran and Stockhammer (2005), Naastepad and Storm (2006), Hein and Vogel (2007), Stockhammer and Ederer (2008), Stockhammer et al. (2009), Hein and Vogel (2009) and several chapters in Chiarella et al. (2006) and Flaschel and Landesmann (2008). More recent contributions include Nikiforos and Foley (2012), Tavani et al. (2011) andOnaran and Galanis (2012).
} 
they call IS) schedule changed over time and the US economy moved from a wage-led regime after the crisis and the war to a conflictual wage-led and then a profit-led regime at the end of the "Golden Age."

Therefore, the empirical examination of the effects of a change in distribution on utilization and growth should take into account these "structural" changes.

\section{SYMBIOSIS AND CYCLES}

Richard Goodwin, in his seminal 1967 article, models the interaction between workers and capitalists after the predator-prey equations that were introduced by Alfred Lotka (1910) and Vito Volterra (1926, 1931) to describe the dynamics of biological systems with symbiotic populations. Goodwin sketches a predator-prey system where "the improved profitability carries the seed of its own destruction by engendering a too vigorous expansion of output and employment, thus destroying the reserve army of labour and strengthening labour's bargaining power." In Goodwin's system, distribution is the predator and unemployment or growth the prey. He argues that the similarity with the original Lotka-Volterra equations is "not entirely formal...the Volterra's problem of the symbiosis of two populations-partly complementary, partly hostile-is helpful in the understanding of the dynamical contradictions of capitalism, especially when stated in a more or less Marxian form” (p.55, emphasis added).

Our model resembles the predator-prey model. It can be seen as a linearized version of the Lotka-Volterra equations. However, it turns Goodwin's formulation on its head. In our specification, it is the "distribution-ledness" - and thus indirectly the growth rate - that is the predator while distribution is the prey. This is a different way of looking at the contradictory nature of the capitalist ecosystem and the difficult symbiosis (partly complementary, partly hostile) within it. This is not meant to be a critique of the closure of Goodwin. On the contrary our model highlights the possibility that the direction of the cycle can be different at different frequencies. 


\section{THE DOUBLE MOVEMENT}

This way of looking at the symbiosis of the two classes within capitalism echoes - at least to a certain extent - the ideas of Karl Polanyi. In The Great Transformation (2001), Polanyi outlines the path of the Western societies from the pre-modern pre-capitalistic 18th century to the 1930s. According to Polanyi in the pre-capitalistic world "the motives and circumstances of productive activities were embedded in the general organization of society" (p.73). Capitalism was accompanied by the emergence of the self-regulating market, which "demands nothing less than the institutional separation of society into an economic and political sphere" (p.74), the disembeddedness of the economic from the political sphere. This movement towards the self-regulating market implied that humans would be under the constant threat of unemployment and starvation. ${ }^{6}$ Moreover, the self-regulating market destroys cultural and other social institutions and this poses an ever deeper threat for humans at the psychological and social levels. For that reason, there was a counter-movement on behalf of the society to protect itself. This counter-movement is spontaneous because in its absence the society would turn into a "heap of ruins" (p. 204). For Polanyi, the New Deal and the emergence of Communism (and also fascism) were part of this counter-movement where the economy is re-embedded in the general organization of the society. In short, Polanyi's argument is that the state of the society behaves like a pendulum that initially moves towards the direction of disembeddedness and then swings back and the economy is re-embedded in the general organization of the society; the double movement consists of these two separate directions of the pendulum.

The argument of the present paper can be seen as a simple formalization of the double movement. The increase in the profit share is related to the domination of the self-regulating market and inevitably leads to a crisis. The society will mobilize to protect itself and there will be counter-movement, which in our model shows up as an increase in the wage share. However, in our model this countermovement can also later lead to a crisis which will make the emergence of the self-regulating market more appealing and will lead to a change in the direction of distribution and an increase in the profit

\footnotetext{
${ }^{6}$ In fact, according to Polanyi, unemployment and starvation were the main discipline mechanisms of the workers who "failed to comply with the rules of wage labor" (p. 225).
} 
share.

Having said this, we should not disregard some important differences between our argument and Polanyi's. First, Polanyi does not frame his argument in class terms. Although he recognizes the importance of classes, he argues that "mere class interests cannot offer... a satisfactory explanation for any long run social process" (p.160). Second, Polanyi's argument was relatively static. When he was writing his book, right before the end of WWII, he was optimistic that the counter-movement had prevailed once and for all and that the push for the utopia of the self-regulating market had failed. In that sense he described only one oscillation of the pendulum. Our argument is more dynamic and examines the possibility that a similar push toward a self-regulating market can re-emerge, as it in fact did after the late $1970 \mathrm{~s}^{7}$

In conclusion, Polanyi's analysis is obviously more comprehensive and rich than the simple model we presented above. Nevertheless, the oscillations that we described in the previous section can be understood as expressions of the Polanyian double movement.

\section{THE KUZNETS HYPOTHESIS}

Another scholar who expressed the optimism of the post-WWII period was Simon Kuznets. His 1955 presidential address to the American Economic Association put forward the hypothesis that as an economy develops inequality originally increases and then decreases (Kuznets, 1955). This is the famous Kuznets curve, an inverse U-shaped curve in the < per capita income, inequality $>$ space. In other words, further growth — at least for the developed countries - means either stable or decreasing inequality. Notice that, like Polanyi, Kuznets describes only one oscillation of the pendulum; the movement towards increasing inequality at the early stages of development and then the "counter-movement" of decreasing inequality.

Kuznets argues that this observed decrease in inequality is surprising given that only the richest part of the population saves a part of their income and therefore someone would expect inequality

\footnotetext{
${ }^{7}$ An examination of neoliberalism through the analytical framework of the double movement can be found in Helleiner (1996), Silver and Arrighi (2003) and Maertens (2008).
} 
to increase because this rentier income would flow only to the top of the distribution. Kuznets, like Polanyi, emphasizes the "legislative interference and political decisions" as a major factor that counteracts the concentration of saving and leads to a decrease in inequality. However, he also stresses the importance of other factors which are not political but are related to the "nature of dynamic economy," like demographics, the importance of service income, and the diminishing importance of agriculture in total output.

Considering that the functional distribution of income is correlated with the size distribution of income and that the profit share increases as inequality increases, our model can explain the hypothesis of Kuznets. The Kuznets curve can be thought of as the left part of the $\pi$ curve in Figure 2 (the part on the left of $t_{2}$ ), where the profit share initially increases and then decreases.

\section{OTHER THEORIES OF LONG SWINGS}

Our model is not meant to be a substitute for every theory of long run fluctuations in distribution and growth. We aspire to shed light on one possible dimension of these fluctuations, and should be viewed as complementary to the theories that have been stated so far. Let us give some examples.

It seems probable that our cycles coincide with what Albert Hirschman calls Shifting Involvements between private interest and public action (Hirschman, 2002). In this book Hirschman describes how disappointment can play a very important role in the choice between private consumption and

public action. He argues that the utility derived from private consumption will tend to be lower than what the individual had expected and that would induce her to seek satisfaction in public action, which in turn is also likely to undershoot the expectations and lead back to the pursuit of pleasure in private interest and private consumption. In that way there is an endogenous shift of involvements between private interest and public action. Hirschman wrote this book in 1982, trying to understand what had caused the shift from the massive social movements of the late 1960s to the withdrawal to the private sphere fifteen years later.

Hirschman's argument can be seen as complementary to ours. The reversal of a trend in income distribution requires some kind of shifting involvements. Similarly, the continuation of a trend requires 
the continuation of a certain kind of involvement. The reversal from an increase in the profit share to an increase in the wage share requires public action and so does the continuation of this direction of distribution. The decrease in the inequality in the 1930s until the 1970s could never have happened without the involvement of the individuals in public action. On the other hand, the withdrawal to the private sphere is a prerequisite for a reversal of this trend, as it occured in the late 1970s. This trend will not change until there is another major shift in involvement.

One important difference between our argument and that of Hirschman is that according to our model the crisis acts as a catalyst for the shifting involvements; a high-profit-share/wage-led crisis will induce the involvement into public action. On the other hand, a high-wage-share/profit-led crisis will contribute to the weakening of the subjects of public action and to the withdrawal to the private sphere.

Similarly, our argument can be viewed through the lenses of Kalecki's "Political Aspects of Full Employment" (1943). Kalecki describes the possibility that capitalists may prefer high unemployment to a government intervention that will decrease unemployment. Although government is not explicitly introduced in our model it is not hard to see how this argument resonates with our own. Essentially, what Kalecki is describing, is a situation like to the left of $t_{0}$ or the right of $t_{3}$ in Figure 2. Despite the crisis, capitalists prefer to push further toward the increase of their power and the share of their income. The influence of the decisions of the government is an obvious part of this process.

Moreover, no account of the long run is complete without an examination of technological change. It was Joseph Schumpeter who first identified a relation between technological change and long waves (see Schumpeter, 2011). We do not think that there is a specific a priori relation between the timing of the Schumpeterian technological waves and the cycles we outlined in the preceding section. Depending on this timing and the kind of technological progress, the Schumpeterian waves might dampen or exacerbate the oscillations of our model. For example, if the tendency for the increase in the wage share in our model coincides with a period of rapid increase in labor productivity, the negative effects on profitability will be ameliorated, and this could lead to an extension of this part of the oscillation. The profitability crisis of the 1970s could have arrived earlier if it was not for the rapid 
productivity increase of the early post-WWII period.

Finally, the oscillations of our model can be dampened or exacerbated by financial cycles à la Minsky and Kindleberger (Minsky, 1975, 1986, Kindleberger and Aliber, 2005) ${ }^{8}$ For instance, the negative effect of an increase in the profit share when the economy is wage-led can be alleviated - at least temporarily — with a wave of financial innovation that will allow the workers to sustain their consumption and contribute to a high level of demand. Something like that happened in the period before the recent crisis in the United States. In the face of a more and more unequal distribution, economic growth was dependent on an increasingly high level of borrowing on behalf of the household sector (especially the bottom $90 \%$ of the household sector). In turn, this pace of borrowing and the extraordinary increase in the debt-to-income ratio of (the bottom $90 \%$ of) the households became possible only because of the two major asset bubbles that supported it. Thus, as our model shows, the deeper root of the now much celebrated secular stagnation is the distribution of income. Given the current distribution of income, the US economy faces the unpleasant choice between a prolonged period of anemic growth or an asset-bubble-fueled expansion that will unavoidably end with another crisis. ${ }^{9}$

\section{CONCLUSION}

This paper discusses the concept of wage- and profit-led growth in the long run. We argue that the relation between distribution of income and growth changes over time. We propose an endogenous mechanism that leads to fluctuations between wage- and profit-led periods. Our argument is based on the assumption that the behavior of income distribution is fundamentally unstable (the more power a class has the greater is its potential to appropriate a larger share of income) and that its direction is influenced by its potential effects on the macroeconomic performance of the economy. On the other hand, within a simple Kaleckian framework, we assumed that changes in distribution affect the propensities

\footnotetext{
${ }^{8}$ The Minskyan financial cycles have a very strong Schumpeterian element. The movement from hedge to speculative and then to Ponzi finance is explained among others by financial innovations. In that sense this kind of long swings is related to the technological swings of the previous paragraph.

${ }^{9}$ For a recent discussion from a Stock-Flow Consistent macroeconomic perspective see Papadimitriou et al. (2014).
} 
to invest and save. As a result the more the profit share increases, the more wage-led the economy becomes, and vice versa.

This is a linear analogue of the Lotka-Volterra predator-prey equations that were utilized by Richard Goodwin. However, in our model the roles of predator and prey have been reversed. We also showed that our argument is a specific formulation of the double movement of Karl Polanyi and is related to the theories of long swings set forth by Simon Kuznets, Michal Kalecki and Albert Hirschman. Finally, an important corollary of this argument is that we need to be careful with the empirical estimation of the effect of a change in distribution on the macroeconomic performance of the economy.

This analytical framework can help us understand the swings in growth and distribution over the last century. Most importantly it can help us solve some puzzles of the present and provide some guidance for the future. 


\section{References}

Amadeo, E. J. (1986). "The Role of Capacity Utilization in the Long Period Analysis," Political Economy 2(2), 147-160.

Barbosa-Filho, N. H. and L. Taylor (2006). "Distributive and Demand Cycles in the U.S. Economy-A Structuralist Goodwin Model," Metroeconomica 57(3), 389-411.

Bowles, S. and R. Boyer (1995). "Wages, Aggregate Demand, and Employment in an Open Economy: an Empirical Investigation," in G.A. Epstein and H. Gintis (Eds.), "Macroeconomic Policy after the Conservative Era," Cambridge, UK: Cambridge University Press.

Boyer, R. (2000). "Is a Finance-led Growth Regime a Viable Alternative to Fordism? A Preliminary Analysis," Economy and society 29(1), 111-145.

Chiarella, C., R. Franke, P. Flaschel, and W. Semmler (Eds.) (2006). "Quantitative and Empirical Analysis of Nonlinear Dynamic Models," Contribution to Economics Analysis, Amsterdam, Elsevier.

Dutt, A. K. (1984). "Stagnation, Income Distribution and Monopoly Power," Cambridge Journal of Economics 8(1), 25-40 (1990). "Growth, Distribution and Uneven Development," Cambridge, UK: Cambridge University Press.

Dynan, K. E., J. S. Skinner, and S. P. Zeldes (2004). “Do the Rich Save More?” Journal of Political Economy 112(2), 397-444.

Epstein, G. A. (2005). "Financialization and the World Economy,” Northampton, MA: Edward Elgar Publishing

Flaschel, P. and M. Landesmann (Eds.) (2008). "Mathematical Economics and the Dynamics of Capitalism," Frontiers of Political Economy, London, Routledge.

Goodwin, R. M. (1967). “A Growth Cycle,” In C. Feinstein (Ed.), “Socialism, Capitalism and Economic Growth,” Cambridge, UK: Cambridge University Press.

Gordon, D. M. (1995). “Growth, Distribution, and the Rules of the Game,” In G. A. Epstein and H. Gintis (Eds.), "Macroeconomic Policy after the Conservative Era," Cambridge, UK: Cambridge University Press.

Hein, E. and L. Vogel (2007). "Distribution and Growth Reconsidered: Empirical Results for Six OECD Countries,” Cambridge Journal of Economics 32(3), 479-511. 
(2009). "Distribution and Growth in France and Germany: Single Equation Estimations and Model Simulations Based on the Bhaduri/Marglin Model," Review of Political Economy 21(2), 245-272.

Helleiner, E. (1996). "States and the Reemergence of Global Finance: From Bretton Woods to the 1990s," Cornell Paperbacks, Ithaca, NY: Cornell University Press.

Hirschman, A. (2002). "Shifting Involvements: Private Interest and Public Action" (reprint ed.), Eliot Janeway Lectures on Historical Economics, Princeton, NJ: Princeton University Press, First publication date: 1982.

Kaldor, N. (1955). "Alternative Theories of Distribution," The Review of Economic Studies 23(2), 83-100.

Kalecki, M. (1937). “The Principle of Increasing Risk,” Economica 4(16), $440-447$.

(1943). "Political Aspects of Full Employment," The Political Quarterly 14(4), 322330.

(1971). "Selected Essays on the Dynamics of the Capitalist Economy," Cambridge, UK: Cambridge University Press.

Keynes, J. M. (2013 [1930]). “A Treatise on Money,” from "The Collected Writings of John Maynard Keynes," Volumes V \& VI., Cambridge University Press.

(2013 [1936]). "The General Theory of Employment, Interest and Money," from "The Collected Writings of John Maynard Keynes," Volume VII, Cambridge University Press.

Kindleberger, C. P. and R. Z. Aliber (2005). “Manias, Panics and Crashes,” Hobiken, NJ: John Wiley \& Sons.

Kurz, H. (1990). “Technical Change, Growth and Distribution,” in H. Kurz (Ed.), "Capital Distribution and Effective Demand: Studies in the Classical Approach to Economic Theory," Cambridge, MA: Basil Blackwell.

Kuznets, S. (1955). "Economic Growth and Income Inequality," American Economic Review $45(1), 1-28$.

Lazonick, W. and M. O’Sullivan (2000). "Maximizing Shareholder Value: a New Ideology for Corporate Governance," Economy and Society 29(1), 13-35.

Lotka, A. J. (1910). "Contribution to the Theory of Periodic Reaction," Journal of Physical Chemistry A 14(3), 271-274.

Maertens, E. (2008). "Polanyi’s Double Movement: A Critical Reappraisal," Social Thought \& Research 29, 129-153. 
Marglin, S. and A. Bhaduri (1990). Profit Squeeze and Keynesian Theory," In S. Marglin and J. Schor (Eds.), "The Golden Age of Capitalism: Reinterpreting the Postwar Experience," Oxford: Clarendon Press.

Minsky, H. (1975). “John Maynard Keynes,” New York: Columbia University Press. (1986). "Stabilizing an Unstable Economy," New Haven, CT: Yale University Press. Naastepad, C. and S. Storm (2006), “OECD Demand Regimes (1960-2000),” Journal of Post Keynesian Economics 29(2), 211-246.

Nikiforos, M. and D. K. Foley (2012). "Distribution and Capacity Utilization: Conceptual Issues and Empirical Evidence," Metroeconomica 63(1), 200-229. Special Issue on Kaleckian Growth Theory.

Onaran, Ö. and G. Galanis (2012). "Is Aggregate Demand Wage-led or Profit-led? (31): National and Global Effects," (International Labour Office, Geneva 2012) Conditions of Work and Employment Series.

Onaran, Ö. and E. Stockhammer (2005). "Two Different Export-oriented Growth Strategies: Accumulation and Distribution a la Turca and a la South Korea," Emerging Markets Finance and Trade 41(1), 65-89.

Orhangazi, Ö. (2008). "Financialisation and Capital Accumulation in the Non-financial Corporate Sector: A Theoretical and Empirical Investigation on the US Economy: 1973-2003," Cambridge Journal of Economics 32(6), 863-886.

Papadimitriou, D. B., M. Nikiforos, G. Zezza, and G. Hannsgen (2014, April). “Is Rising Inequality a Hindrance to the US Economic Recovery?, Strategic Analysis, Levy Economics Institute.

Piketty, T. (2014). "Capital in the Twenty-First Century," Cambridge, MA: Harvard University Press. Polanyi, K. (2001). "The Great Transformation: The Political and Economic Origins of Our Time,” Boston, MA: Beacon Press, first publication date: 1944.

Ramsey, F. P. (1928). “A Mathematical Theory of Saving,” The Economic Journal 38(152), 543-559.

Rowthorn, R. (1981). "Demand Real Wages and Economic Growth,” Thames Papers in Political Economy.

Samuelson, P. A. (1939). "A Synthesis of the Principle of Acceleration and the Multiplier," Journal of Political Economy 47(6), 786-797.

Sánchez, J. M. and E. Yurdagul (2013). “Why Are Corporations Holding So Much Cash?” The Regional Economist, Federal Reserve Bank of St. Louis, 21(1), 4-8.

Schumpeter, J. (2011). "The Theory of Economic Development: An Inquiry into Profits, Capital, Credit, Interest, and the Business Cycle," Social Science Classics, Piscataway, 
NJ: Transaction Publishers. first publication in English: 1934, introduction by J.E. Elliott.

Silver, B. J. and G. Arrighi (2003). "Polanyi's 'double movement': The Belle Époques of British and US Hegemony Compared,” Politics \& Society 31(2), 325-355.

Skott, P. and S. Ryoo (2008). "Macroeconomic Implications of Financialisation," Cambridge Journal of Economics 32(6), 827-862.

Steindl, J. (1952). "Maturity and Stagnation in American Capitalism,” Oxford: Basil Blackwell.

Stockhammer, E. (2004). "Financialisation and the Slowdown of Accumulation," Cambridge Journal of Economics 28(5), 719-741.

Stockhammer, E. and S. Ederer (2008). "Demand Effects of the Falling Wage Share in Austria," Empirica 35(5), 481-502.

Stockhammer, E. and O. Onaran (2004). "Accumulation, Distribution and Employment: a Structural VAR approach to a Kaleckian Macro Model," Structural Change and Economic Dynamics 15(4), 421-447.

Stockhammer, E., O. Onaran, and S. Ederer (2009). "Functional Income Distribution and Aggregate Demand in the Euro Area," Cambridge Journal of Economics 33(1), 139159.

Tavani, D., P. Flaschel, and L. Taylor (2011). "Estimated Non-linearities and Multiple Equilibria in a Model of Distributive-Demand Cycles, "International Review of Applied Economics 25(5), 519-538.

Taylor, L. (1983). “Structuralist Macroeconomics,” New York: Basil Books. (1990). "Real and Money Wages, Output and Inflation in the Semi-Industrialized World," Economica 57(227), 329-353.

(2004). "Reconstructing Macroeconomics: Structuralist Proposals and Critiques of the Mainstream," Cambridge, MA: Harvard University Press.

Volterra, V. (1926). "Variazioni e Fluttuazioni del Numero d'Individui in Specie Animali Conviventi," Memorie dell'Accademia Nazionale dei Lincei 2, 31-113. (1931). "Variations and Fluctuations of the Number of Individuals in Animal Species Living Together,” In R. Chapman (Ed.), Animal Ecology. McGraw-Hill. 